\title{
Do parents provide a helping hand to vocabulary development in bilingual children?
}

\author{
Valery LIMIA ${ }^{1 \star}$, Şeyda ÖZÇALIŞKAN ${ }^{1}$, and Erika HOFF² \\ ${ }^{1}$ Department of Psychology, Georgia State University and ${ }^{2}$ Department of Psychology, Florida Atlantic \\ University \\ ${ }^{*}$ Corresponding Author. Valery Limia, MA, Department of Psychology, Georgia State University, PO Box \\ 5010, Atlanta, GA 30302. E-mail: vmateo2@student.gsu.edu
}

(Received 9 November 2017; revised 29 August 2018; accepted 10 December 2018;

first published online 11 March 2019)

\begin{abstract}
Monolingual children identify referents uniquely in gesture before they do so with words, and parents translate these gestures into words. Children benefit from these translations, acquiring the words that their parents translated earlier than the ones that are not translated. Are bilingual children as likely as monolingual children to identify referents uniquely in gesture; and do parental translations have the same positive impact on the vocabulary development of bilingual children? Our results showed that the bilingual children - dominant in English or in Spanish - were as likely as monolingual children to identify referents uniquely in gesture. More importantly, the unique gestures, when translated into words by the parents, were as likely to enter bilingual and monolingual children's speech - independent of language dominance. Our results suggest that parental response to child gesture plays as crucial of a role in the vocabulary development of bilingual children as it does in monolingual children.
\end{abstract}

Keywords: bilingual; gesture vocabulary; Spanish

\section{Introduction}

Young children learning only one language often display their readiness to learn a particular concept in gesture before conveying the same concept in speech (Iverson \& Goldin-Meadow, 2005; Özçalışkan \& Goldin-Meadow, 2005a). Parents respond to these gestures, often translating the gestures a child produces without speech into words. Children benefit from these translations, showing earlier mastery of the concept if given the targeted instruction than if not given the instruction (Goldin-Meadow, Goodrich, Sauer, \& Iverson, 2007) - an effect that holds across children with different developmental profiles (Dimitrova, Özçalışkan, \& Adamson, 2016). The question still remains about the factors that explain the close association between children's gestures and parent linguistic input, particularly in contexts where children are acquiring two languages simultaneously. In this study, we focus on the speech and gestures produced by parent-child dyads of English-Spanish (c) Cambridge University Press 2019 
dual-language learners (hereafter 'bilingual children'), in comparison to parent-child dyads of children learning only one language (English or Spanish); we ask whether parental response to child gesture plays the same role in helping vocabulary development in bilingual children as it does in monolingual children. This study expands our understanding of key factors that contribute to language development in children growing up in bilingual environments.

\section{Gesture production in young monolingual and bilingual children}

Children take their first steps into language with their hands. Monolingual children use gestures to convey a multitude of meanings before they can do so with words (Acredolo \& Goodwyn, 1985; Bates, 1976; Petitto, 1992). Their early gesture repertoires largely consist of DEICTIC GESTURES that indicate referents (e.g., pointing to an object; Tomasello, Carpenter, \& Liszkowski, 2007) and GIVE GESTURES (extending empty open palm near an object) that request them, along with a few CONVENTIONAL GESTURES that convey culturally prescribed meanings (e.g., shake head for negation; Bates, Benigni, Bretherton, Camaioni, \& Volterra, 1979; Iverson, Capirci, \& Caselli, 1994; Özçalışkan \& Goldin-Meadow, 2005b). The early and frequent use of deictic and give gestures that identify objects are also accompanied by the appearance of iconic gestures conveying action meanings beginning around ages 2;6-3;0 (e.g., moving empty hand repeatedly to mouth to convey eating; Özçalışkan, Gentner, \& Goldin-Meadow, 2014; Özçalışkan \& Goldin-Meadow, 2011). During this period of development, gestures - particularly deictic and give gestures - serve as the primary mechanism through which young monolingual children communicate about referents. More importantly, children express a different set of meanings in their gestures than in their speech, with a greater range of meanings conveyed in gesture than in speech (Iverson et al., 1994; Özçalışkan, Adamson, Dimitrova, \& Baumann, 2017).

Gesture also plays a distinct role in language development by predicting later language skills in monolingual children - a pattern that becomes particularly pronounced for gestures that indicate (e.g., point at bottle) or request (e.g., extend empty palm requesting bottle) referents. For example, the more referents a child indicates with gestures at 14 months, the larger the child's vocabulary size will be in subsequent years (Rowe, Özçalışkan, \& Goldin-Meadow, 2008) - a predictive relation that remains robust across monolingual children with different developmental profiles (Özçalışkan, Adamson, \& Dimitrova, 2016). Similarly, the earlier a child identifies an object in gesture (e.g., point at bottle), the earlier the same child will produce the verbal label for that object (e.g., bottle; Iverson \& Goldin-Meadow, 2005) - a pattern that remains unchanged even among monolingual children who produce considerably fewer gestures (i.e., children with autism and Down Syndrome; Özçalışkan et al., 2017). In sum, gestures - particularly gestures that identify objects - not only provide a transitional medium to communicate about referents, but also predict the content and size of monolingual children's emerging vocabularies in speech.

Unlike their monolingual peers, children growing up in dual-language environments face the task of learning two sets of vocabularies in their two languages (Pearson, Fernández, \& Oller, 1993; Weiten, 2007). The question remains, however, whether gesture plays a similar role in the vocabulary development of bilingual children, preceding and predicting the emergence of new vocabulary items in their speech. Existing studies suggest that bilingual children produce similar types of gestures and at relatively similar distributions at the early ages. Similar to their monolingual peers, 
bilingual children initially produce gestures that indicate or request referents and some conventional gestures around age 1;0, followed by iconic gestures that emerge around ages 2;0-3;0 (Nicoladis, Mayberry, \& Genesee, 1999). Gestures that identify objects, particularly deictic gestures, constitute the most frequently used gesture type, accounting for $80 \%$ of bilingual children's overall gesture production (Mayberry \& Nicoladis, 2000; Nicoladis et al., 1999) - a production pattern that is also observed in monolingual children (Iverson et al., 1994; Özçalışkan \& Goldin-Meadow, 2005b).

There is, however, relatively little work that examined the link between early gesture and subsequent vocabulary development in bilingual children. The few existing studies largely focused on the relation between children's gesture use and the complexity of their speech production. Overall, these studies suggest that, as bilingual children's speech becomes increasingly advanced in one of their two languages, their gesturing in that language becomes more complex as well (Mayberry \& Nicoladis, 2000). For example, Nicoladis and colleagues (1999) found that two-year-old French-English bilingual children, when interacting with their parents in a free play context, produced more of the relatively more complex iconic gestures in their dominant language than in their weaker language - a pattern that was reversed for the production of the less complex deictic gestures. Children's production of iconic gestures - but not other gestures - was also positively related to the complexity of their speech production (i.e., Mean Length of Utterance (MLU)). A similar pattern of results was also observed in a study with older French-English bilingual children (Nicoladis, 2002): children used more conventional and deictic gestures when speaking their weaker language, and more iconic gestures when speaking their stronger language, further suggesting that different gesture types might become more prevalent depending on whether the child is speaking the weaker or the stronger language. Aside from these few studies that examined children's relative production of different gesture types in relation to the complexity of their speech, not much is known about the link between children's early gestures and subsequent vocabulary development. More specifically, we still do not know whether bilingual children's early gestures precede and predict their emerging vocabularies in speech, and, if so, whether this predictive relation between gesture and speech shows variability by language dominance.

\section{Parental response to child gesture and its effects on monolingual and bilingual children's vocabulary}

The early gestures monolingual children produce predict the content and size of their vocabularies in speech (Iverson \& Goldin-Meadow, 2005; Özçalışkan et al., 2016, 2017; Rowe et al., 2008). But what might underlie this phenomenon? As suggested by earlier work (Özçalışkan, Adamson, Dimitrova, \& Baumann, 2018; Özçalışkan \& Goldin-Meadow, 2005b, 2006, 2011), parents, who are highly responsive to the gestures their children produce, can play an important role in this process.

Parents routinely glean information from their children's gestures. In fact, when their children gesture to referents they cannot yet express in speech, parents frequently respond by providing the spoken labels for the gestured referents (Masur, 1982). Children benefit from these verbal responses parents provide to their gestures and learn the words for the referents earlier if given the targeted parental verbal response than if not given the response (Goldin-Meadow et al., 2007). Specifically, the unique gesture referents children produce (e.g., child points to a cup), when translated into words by the parent (e.g., "Do you want the cup?"), are more likely to enter 
children's vocabularies as words than gesture referents that are not translated (Goldin-Meadow et al., 2007; see also Masur, 1982) - a pattern that remains robust even in children with markedly different gesture production profiles. More specifically, parents of children with developmental disorders (e.g., autism, Down Syndrome) - regardless of large differences in their children's rates of unique gesture production - are just as likely to provide verbal responses to their children's unique gesture referents as parents of typically developing children. These gestures that are translated into words are, in turn, more likely to appear in children's vocabularies as words than the ones that are not translated by the parents (Dimitrova et al., 2016). These studies thus suggest that, for monolingual children, targeted parental verbal response to child gesture might serve as an important scaffold for acquiring new vocabulary items in the spoken modality.

Compared to several studies with monolingual children, research on targeted verbal input to the gestures of bilingual children remains fairly sparse. In fact, the majority of the earlier work focused primarily on the overall verbal input to bilingual children, leaving parental verbal input targeted specifically to child gesture unexamined. Not surprisingly, the overarching finding across several such studies was that, when overall parental verbal input is not balanced for the child's two languages, the child becomes more proficient (i.e., dominant) in one language, and shows weaker spoken language abilities in the other (Hammer, Davison, Lawrence, \& Miccio, 2009; Hoff et al., 2012; Oller \& Eilers, 2002). For example, Oller and Eilers (2002) found that five- to ten-year-old bilingual children in the United States, whose parents spoke only Spanish at home, developed larger vocabularies in Spanish and smaller vocabularies in English than children whose parents spoke English and Spanish at comparable rates. Similarly, Hammer et al. (2009) found that when Hispanic mothers in the United States used more English than Spanish, their four-year-old children showed slower rates of Spanish vocabulary growth and lower vocabularies in Spanish - a pattern that was reversed for children whose mothers continued to speak to them in Spanish. In more recent work, Hoff et al. (2012) showed this pattern to be evident even in younger bilingual children. The amount of language input bilingual children aged 1;10 received in their two languages (Spanish, English) was also a good predictor of the size of their lexicons in their two languages. Overall, existing studies show close coupling between amount of parental verbal input and the size of children's vocabularies in their two languages. However, there is no work that has examined the role targeted parental verbal input to child gesture can play in vocabulary development. Consequently, we do not yet know whether parents of bilingual children show similarities to parents of monolingual children in how often they respond to and translate their children's gestures into words, and, if so, whether these translations positively influence children's subsequent vocabularies in each of their two languages.

\section{The present study}

Children's early gesture production and targeted parental verbal responses that translate these gestures into words play an important role in subsequent vocabulary development of children learning only one language. In this study, we take this finding one step further and ask whether parental response to child gesture might play a similar role in the vocabulary development of children learning two languages. We focus on the gestures produced by children acquiring English and Spanish simultaneously; 
comparing them to the gestures produced by children learning only English or only Spanish as their native language, and examine the effect parental verbal response to such gestures has on children's subsequent vocabulary development.

We first ask whether bilingual children show a pattern akin to monolingual children in their production of unique gestures. Based on previous work that shows relatively high and comparable proportion of unique gesture use among monolingual children with markedly different gesture production rates (Özçalışkan et al., 2017), we predict that bilingual children will express a comparable proportion of referents uniquely in gesture, compared to monolingual children speaking either Spanish or English.

Second, we ask whether parents of bilingual children are as likely as parents of monolingual children to translate their children's unique gesture referents into words. We predict that parents of bilingual children will produce similar proportions of translations for their children's gestures as parents of monolingual children, based on earlier work (Dimitrova et al., 2016) that showed no differences in parental verbal response to child gesture in monolingual children with markedly different gesture production profiles.

Third, we ask whether parents' verbal translations will increase the likelihood of the referents conveyed uniquely in gesture subsequently entering bilingual children's emerging spoken vocabularies as words, at rates comparable to monolingual children. We predict that the gesture referents that parents translate will be more likely to enter bilingual children's spoken vocabularies as words than the gesture referents not translated by the parents, and at rates comparable to monolingual children, following a pattern observed in monolingual children with different developmental profiles (Dimitrova et al., 2016).

Last, we ask whether the aforementioned patterns would differ by language dominance. Based on earlier work (Nicoladis, 2002) that showed greater use of deictic gestures indicating referents in children's weaker language, we predict that bilingual children would indicate a greater proportion of referents uniquely in gesture in their weaker language - be it Spanish or English. Also, based on earlier work that showed no variability in parental verbal input to child gesture across children with different gesture production profiles (Dimitrova et al., 2016), we predict that there will be no differences in the proportion of parental verbal response to child gesture in the children's weaker vs. stronger language. Consequently, we predict that translated gesture referents would be more likely to enter children's vocabularies as words than the ones that are not translated and at similar rates in both their stronger and weaker language.

\section{Methods}

\section{Sample}

The sample included 34 Spanish-English bilingual children-dominant in English $\left(n=17, M_{\mathrm{AGE}}\right.$ AT INITIAL OBSERVATION $=2 ; 6,10$ boys $)$ or in Spanish $(n=17$, $M_{\mathrm{AGE}}$ AT INITIAL OBSERVATION $=2 ; 6,9$ boys) and 34 monolingual children - with either English $\left(n=17, M_{\mathrm{AGE}}\right.$ AT INITIAL OBSERVATION $=2 ; 6,10$ boys) or Spanish ( $n=17, M_{\mathrm{AGE}}$ AT INITIAL OBSERVATION $=2 ; 6,8$ boys $)$ as their native language, along with their parents. The 68 children ( 34 bilingual, 34 monolingual) selected for this study came from a larger longitudinal study following language development of 232 children in South Florida (Hoff, 2017). The 34 bilingual children were selected so 
that they were dominant only in one language, and were also comparable to the 34 monolingual children in their vocabulary, assessed by the Expressive One-Word Picture Vocabulary Test (EOWPVT; Brownell, 2001; $M_{\text {MONOLINGUAL }}=20.68$ [SD = $14.28]$ vs. $\left.M_{\text {BILINGUAL }}=15.47,[S D=10.87], t(66)=1.69, p=.10\right)$, gender, and family socioeconomic status (SES). The two groups of bilingual children (Spanish dominant, English dominant) were also comparable in their total vocabulary size across their two languages (EOWPVT; $M_{\text {ENGLISH }}$ DOMINANT $=14.82 \quad[S D=10.02]$ vs. $\left.M_{\text {SPANISH DOMINANT }}=16.12[S D=11.92], t(32)=0.34, p=.73\right]$.

Language dominance of bilingual children was assessed with the McArthur Bates Communicative Development Inventory in English (MCDI; Fenson et al., 2007) and Inventario Del Desarollo de Habilidades Comunicativas Inventario in Spanish (IDHC; Jackson-Maldonado et al., 2005) at the initial observation for the majority of the bilingual children (28/34: 82\%). The parent who knew the child's ability in each language the best completed the parent report for that language, which resulted in either the same parent (mother or father) completing the report in both languages (18/34: 53\%) or different parents (or a grandparent in a few cases) completing the report in each language (10/34: 30\%). For a few of the children (6/34:18\%), the parent did not complete either the MCDI or IDHC. For these children, we used their vocabulary scores on the EOWPVT (Brownell, 2001) to assess dominance in their two languages at the initial observation. Bilingual children who had larger vocabulary scores in one language $\left(M_{\text {PERCENT DIFFERENCE IN VOCABULARY SCORES }}=\right.$ $49 \%[S D=29 \%]$, range $=1-100 \%)$ were considered dominant in that language.

We further confirmed the assignment of the bilingual children as being dominant in English or Spanish, using their actual word production (i.e., number of words token and types they produced in each language) in parent-child interaction at initial observation at child age 2;6. The English-dominant bilinguals produced a greater number of word tokens $\left[M_{\mathrm{ENGLISH}}=548.94\right.$ vs. $\left.M_{\mathrm{SPANISH}}=159.06 ; t(16)=4.82, p<.001\right]$ and word types $\left[M_{\mathrm{ENGLISH}}=133.82\right.$ vs. $\left.M_{\mathrm{SPANISH}}=54.05 ; t(16)=5.27, p<.001\right]$ in English than in Spanish. Spanish-dominant bilingual children, on the other hand, produced a greater number of word tokens $\left[M_{\mathrm{SPANISH}}=607.655\right.$ vs. $M_{\mathrm{ENGLISH}}=248.35$; $t(16)=-3.25, p<.001]$ and word types $\left[M_{\mathrm{SPANISH}}=147.82\right.$ vs. $M_{\mathrm{ENGLISH}}=82.00$; $t(16)=5.27, p<.05]$ in Spanish than in English. The bilingual children's MCDI, IDHC, and EOWPVT scores in English and Spanish also showed strong positive correlations with the token and type frequencies of words that they produced in each language during parent-child interaction at initial observation (see the correlational table in the 'Appendix').

Our criterion for selection of participants was based on their vocabulary size at initial observation at child age 2;6. Importantly, however, children's dominance shifted over time, particularly for the Spanish-dominant children (see Table 1). Spanish-dominant children, who produced significantly greater number and variety of words in Spanish than in English at age 2;6, did not differ reliably in their vocabularies in their two languages - both for word tokens $\left[M_{\mathrm{ENGLISH}}=699.92 \mathrm{vs}\right.$. $\left.M_{\text {SPANISH }}=508.67 ; t(11)=1.75, p=.11\right]$ and word types $\left[M_{\mathrm{ENGLISH}}=181.58\right.$ vs. $M_{\text {SPANISH }}=152.92 ; t(11)=1.58, p=.14$ ] - at age $3 ; 6$. English-dominant children, on the other hand, remained dominant in English, continuing to produce a significantly greater number [i.e., tokens; $M_{\mathrm{ENGLISH}}=966.25$ vs. $M_{\mathrm{SPANISH}}=231.69 ; t(15)=6.23$, $p<.01$ ] and variety of words [i.e., types; $M_{\mathrm{ENGLISH}}=218.00$ vs. $M_{\mathrm{SPANISH}}=75.25$; $t(15)=6.29, p<.01]$ in English than in Spanish at age 3;6. 
Table 1. Mean distribution (and standard deviation) of vocabulary production by Spanish- and English-dominant bilingual children during parent-child interactions by child age

\begin{tabular}{|c|c|c|c|c|c|c|}
\hline & \multicolumn{3}{|c|}{ Vocabulary in English } & \multicolumn{3}{|c|}{ Vocabulary in Spanish } \\
\hline & $2 ; 6$ & $3 ; 0$ & $3 ; 6$ & $2 ; 6$ & $3 ; 0$ & $3 ; 6$ \\
\hline \multicolumn{7}{|c|}{ English-dominant } \\
\hline Word types & $133.82(47.04)$ & $188.15(45.85)$ & $218.00(49.12)$ & $54.06(38.46)$ & $59.65(58.99)$ & $70.82(73.23)$ \\
\hline \multicolumn{7}{|c|}{ Spanish-dominant } \\
\hline Word types & $82.00(33.87)$ & $135.85(50.51)$ & $181.58(33.90)$ & $147.82(65.10)$ & $118.06(81.71)$ & $152.92(43.20)$ \\
\hline
\end{tabular}


The vast majority of parents of bilingual children were Spanish monolinguals (85\% of mothers, $59 \%$ of fathers) or English monolinguals (12\% of mothers, 38\% of fathers); the few remaining parents were either Spanish-English bilinguals (3\% of mothers) or monolingual speakers of a language other than Spanish or English (3\% of fathers). Most of the bilingual children in our study (70\%) heard English and Spanish in the home from either one or both parents, and the few remaining children heard one language from one parent and the other language from the other parent $(12 \%)$, or one language from one parent and the other language from a grandparent (18\%). The majority of the parents in both groups had either college (monolingual: 17/34; bilingual: 17/34) or high school degrees (monolingual: 10/34; bilingual: $8 / 34$ ).

\section{Data collection}

Child-parent dyads were video-recorded three times - from child age 2;6 to 3;6 - with 6-month intervals, as they interacted with a set of toys (i.e., barn with animals, picnic set, picture-book) provided by the experimenter. Parents were asked to play as naturally as possible with their children using each toy, resulting in an average playtime of 30 minutes per observation. The same three toys were used at each visit to avoid context effects on language production.

Monolingual child-parent dyads were observed once at each observation. Bilingual child-parent dyads were observed twice at each observation, but on two different days, once in English and once in Spanish. Both children and their parents were instructed to speak only the language of the interaction (i.e., English only vs. Spanish only) without mixing languages. Parents rarely switched languages, mixing on less than $2 \%$ of their utterances. However, all 34 of the bilingual children mixed English and Spanish during their interactions with their parents, rather than speaking one language per interaction as instructed. The majority of the bilingual children in our study $(71 \%)$ interacted with the same parent in both interactions, and in most cases this was the mother. Parents completed the MCDI in English (Fenson et al., 2007) and/or IDHC in Spanish (Jackson-Maldonado et al., 2005) at the initial observation. Children completed the EOWPVT (Brownell, 2000, 2001) both at initial (child age 2;6) and final (child age 3;6) observation.

\section{Transcription and coding}

All parent-child videos were transcribed for speech using the Codes for Human Analysis Transcript (CHAT; MacWhinney, 2000). Sounds that referred to entities, properties, or events (e.g., doll), onomatopoeic sounds (e.g., meow), and evaluative sounds (e.g., woops) were transcribed and counted as words. Meaningless sounds, such as babbling and non-communicative noises (e.g., laughing, gasping) were not counted as words. However, incomplete sounds that were intelligible (e.g., anana for banana) were also counted as words.

All gestures produced by children at the initial observation (age $2 ; 6$ ) were also coded. Gesture was defined as a communicative hand movement that did not directly manipulate objects (e.g., twisting a bottle open; Özçalışkan \& Goldin-Meadow, 2005a). The only exceptions were the hold-up gestures (hold-up bottle to show to parent); these gestures served the same function as pointing gestures by drawing the observer's attention to objects, and were also coded as gestures, following Özçalışkan 
and Goldin-Meadow. In this study, we focused on two types of gestures that conveyed information about objects, namely DEICTIC gestures that indicated objects (i.e., pointing at or holding up a toy) and GIVE gestures that requested objects (i.e., extending open palm to request a toy), following earlier work (Dimitrova et al., 2016). Conventional gestures that conveyed culturally prescribed meanings (e.g., nodding head for negation) and the few ICONIC gestures that conveyed action meanings (e.g., thrusting open palm forward for throwing) were excluded from the analysis, as they did not convey object information.

\section{Child unique gesture vocabulary at initial observation}

We further classified all deictic and give gestures at initial observation as identifying either (1) a referent not yet expressed in speech (e.g., child points to a doll but does not yet produce the word doll at initial observation) or (2) a referent already expressed in speech (e.g., child points to a doll and produces the word doll during the same initial observation). The referents that were expressed in both speech and gesture (doll + point at doll) during the same observation were excluded $\left(M_{\text {MONOLINGUAL }}=4.67, S D=4.14 ; M_{\text {BILINGUAL }}=5.86, S D=3.49\right)$ from all analyses, because we could not determine whether they appeared first in speech or in gesture. We then focused only on the gesture referents the child did NOT yet label in speech, creating a 'unique gesture vocabulary' for each individual child.

\section{Parental response to child unique gesture at the initial observation}

We identified parental verbal response to each unique gesture referent the child produced (e.g., point at doll) at initial observation, and coded it as either TRANSLATING (e.g., "That is a pretty doll") or NOT TRANSLATING (e.g., "I will get it") the child's unique gesture referent into words during the same observation, following earlier work (Dimitrova et al., 2016; Goldin-Meadow et al., 2007).

\section{Child speech vocabulary at subsequent observations}

We coded each child's speech production at the two subsequent observations (ages 3;0 and 3;6) for the appearance of words that were initially conveyed uniquely in gesture at initial observation. The unique gesture referents children produced at the initial observation were coded as either ENTERING or NOT ENTERING the child's spoken vocabulary as words in the two subsequent observation sessions.

\section{Reliability}

One coder coded all responses. A second coder, blind to the hypotheses of the study, coded responses for a randomly selected $15 \%$ of the data, separately for each group. Reliability was $86 \%(k=.86)$ for detecting gesture, 98\% $(k=.98)$ for classifying gesture into types, 95\% $(k=.94)$ for assigning meaning to gesture, $96 \%(k=.95)$ for identifying referents uniquely expressed in gesture, 92\% $(k=.86)$ for parental translations of child unique gesture referents, and 93\% $(k=.84)$ for identifying gesture referents entering children's speech as words.

\section{Data analysis}

We computed the number of unique gestures each child produced and the number of verbal responses each parent produced that TRANSLATED or DID NOT TRANSLATE each child's unique gesture referents at child age $2 ; 6$. We then computed the number of 
unique gesture referents that DID or DID NOT enter children's spoken vocabularies as words at child age 3;0 and 3;6. For the bilinguals, we tallied each of these three measures (i.e., unique gestures, translations, and spoken words), separately for English and Spanish. For example, if a bilingual child pointed at a cat during both the Spanish and English language interaction without yet producing the word for it in either language, we counted it as two unique gestures. This was an important criterion as the child's unique gesture vocabulary differed from one language to another depending on what they were capable of producing as words in each of their two languages. Similarly, in subsequent visits, if the same child produced the word cat in English and gato in Spanish interaction, we also counted these as two separate referents entering children's vocabularies as words - one in each language. Our decision to identify vocabulary items in speech separately in the two languages was based on earlier work (Core, Hoff, Rumiche, \& Señor, 2013), which treated each vocabulary item in bilingual children's repertoires in their two languages as different words (e.g., cat vs. gato) - as each word involves different phonological and semantic representations.

The observation time for the bilingual parent-child dyads was twice as long as the monolingual parent-child dyads (30 vs. 60 minutes) as they interacted in each of their two languages separately. To account for the difference in the length of the observation sessions, we converted all raw frequencies into proportions for (1) CHILD UNIQUE GESTURE VOCABULARY by dividing the number of referents identified only in gesture by the total number of referents identified only in gesture and only in speech, (2) PARENT TRANSLATIONS OF CHILD'S UNIQUE GESTURES by dividing the number of parent translations by the total number of child unique gestures, and (3) the translated UNIQUE GESTURE REFERENTS ENTERING CHILD'S SPOKEN VOCABULARY as words by dividing the number of translated gesture referents that entered children's speech by the total number of all translated gestures that did or did not enter children's vocabularies as words, separately for each parent-child dyad. We then arcsine transformed the scores, and conducted all analysis on the transformed scores.

We first analyzed group differences between all monolinguals (collapsing across English and Spanish) and all bilinguals (collapsing across Spanish-dominant and English-dominant bilinguals) to determine whether patterns of child unique gesture production and effect of parental translation of such gestures on children's subsequent spoken vocabularies remain similar in the two groups. We analyzed group differences in children's unique gesture production and parental translations of these unique gestures using one-way ANOVAs - with group (monolingual, bilingual) as a between-subjects factor. We also examined the effect of parents' translations on the likelihood of gestured referents entering children's spoken vocabularies as words using a two-way ANOVA with translation (translated, non-translated) as within- and group (monolingual, bilingual) as between-subjects factors.

We next focused only on the bilinguals and analyzed whether language dominance has any effect on the patterns of gesture and speech production. We examined differences in bilingual children's production of unique gesture referents and parental translations of these unique gestures at initial observation with two-way ANOVAs with dominance (stronger, weaker) as within- and language group (English Dominant, Spanish Dominant) as between-subjects factors. We also examined effect of parental translation on the appearance of unique gesture referents as words in the child's stronger vs. weaker language in the subsequent two observations, with a three-way ANOVA with dominance (stronger, weaker) and translation (translated vs. not translated) as withinand language group (English Dominant, Spanish Dominant) as between-subjects factors. 


\section{Results}

Does parental translation of child gesture play a similar role in children's subsequent speech vocabulary in monolinguals and bilinguals?

We first asked whether bilingual children would be as likely as monolingual children to identify referents uniquely in gesture before they did so with words. In line with our prediction, we found that bilingual children identified a similar proportion of referents uniquely in gesture as their monolingual peers, showing no effect of group $(F(1,67)=0.75, p=.38$; see Figure $1 \mathrm{~A})$.

We next asked whether parents of bilingual children were as likely as parents of monolingual children to translate their children's unique gestures into words. As Figure 1B shows, parents of bilingual children provided a similar proportion of targeted verbal responses to their children's unique gestures as parents of monolingual children, with no group differences $(F(1,67)=1.43, p=.24)$.

We last asked whether the unique gesture referents parents translated into speech were more likely to enter bilingual children's vocabularies as words than the ones that were not translated and at similar rates as monolingual children. As can be seen in Figure 1C, the effect of parent translation of child gesture on children's subsequent vocabulary showed an effect of translation $\left(F(1,66)=24.10, p<.01, \eta_{\mathrm{p}}^{2}\right.$ $=.27$ ), but no effect of group $(F(1,66)=1.07, p=.30)$, and no interaction between group and translation $(F(1,66)=2.28, p=.14)$. The unique gestures translated into words by parents were more likely to enter children's spoken vocabularies as words than the ones that were not translated.

Overall these results show that bilingual children were as likely as monolingual children to indicate referents uniquely in gesture, most of which were translated into words by their parents. More importantly, the translated unique gesture referents children produced were more likely to become part of their spoken vocabularies as words over the next year compared to the non-translated gesture referents - a pattern that remained robust across both monolingual and bilingual children.

\section{Does parental translation of child gesture play a similar role on child's subsequent vocabulary in bilinguals' stronger vs. weaker language?}

We next focused only on the 34 bilingual children, half of whom were dominant in Spanish and the other half in English. We first asked whether bilingual children were as likely to express referents uniquely in gesture in their weaker language as they do in their stronger language. Our analysis showed no effect of dominance $(F(1,32)=0.16, p=.69)$, language group $(F(1,32)=0.98, p=.33)$, or dominance $\times$ language group interaction $(F(1,32)=$ $2.82, p=.10)$ in children's production of unique gestures. That is, bilingual children were comparable in their production of unique gestures in their weaker and stronger languages - regardless of that language being Spanish or English (see Figure 2A).

We next asked whether parents' translations of bilingual children's unique gestures showed an effect of dominance and also found no effect of dominance $(F(1,32)=0.01$ $p=.98)$, language group $(F(1,32)=0.23, p=.60)$, or dominance $\times$ language group interaction $(F(1,32)=0.74, p=.40)$, suggesting that parents were as likely to translate their children's unique gestures in their weaker language as they did for their stronger language - be it Spanish or English (see Figure 2B).

Turning last to the appearance of translated unique gesture referents in bilingual children's spoken repertoires as words, we found an effect of translation $(F(1,32)=$ 9.57, $\left.p=.04, \eta_{\mathrm{p}}^{2}=.23\right)$ - with greater proportion of referents that were translated 
Figure 1. Mean proportion of referents children identified uniquely in gesture at 2;6 (panel A), mean proportion of unique child gestures parents translated into words at 2;6 (panel B), and mean proportion of unique gestures entering children's speech as words at ages 3;03;6 (panel C) for monolinguals (left bars) and bilinguals (right bars); error bars represent standard error.
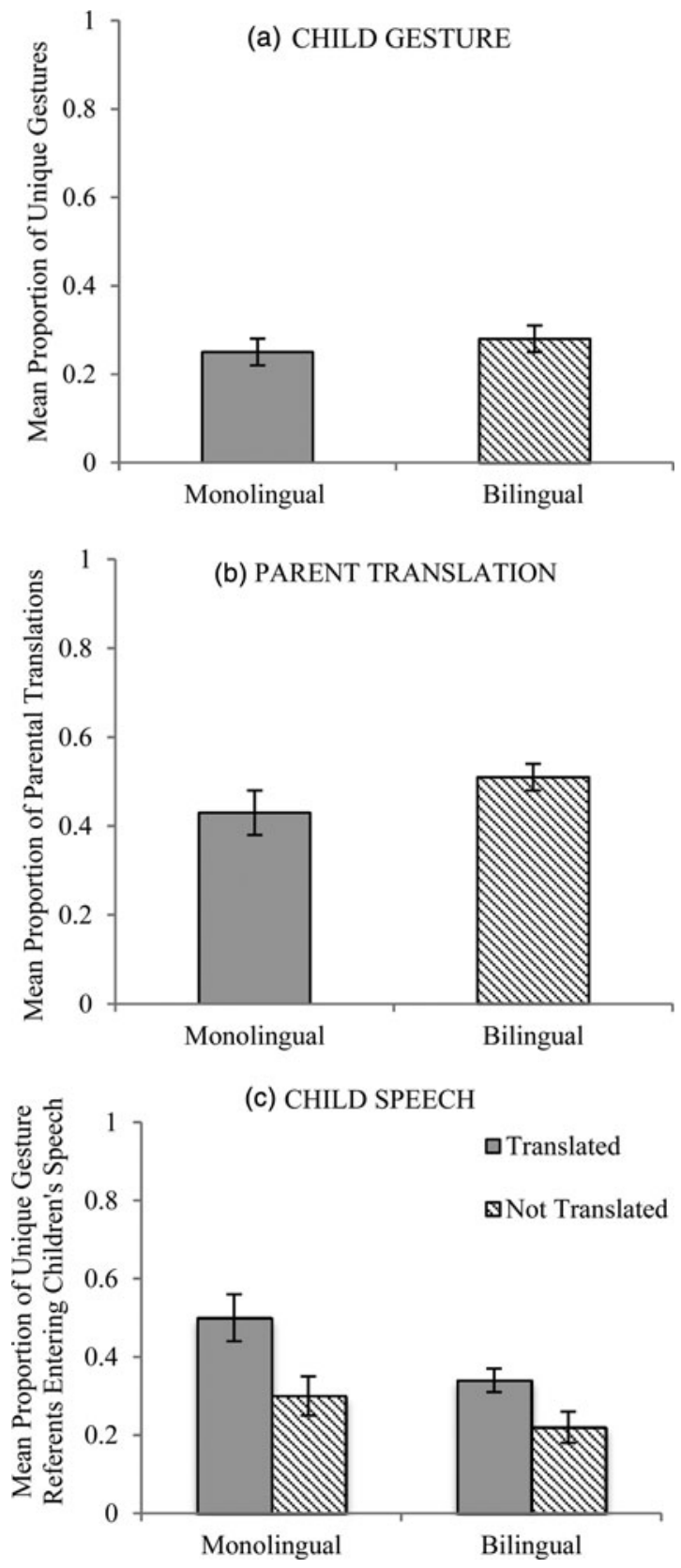

entering children's vocabularies as words than the ones that were not translated (see Figure 2C). We found no effect of language group (Spanish dominant vs. English dominant; $F(1,32)=0.03, p=.86$ ), but an effect of dominance (weaker vs stronger; $\left.F(1,32)=3.98, p=.06, \eta_{\mathrm{p}}^{2}=.11\right)$, which interacted with language group 
(a) CHILD GESTURE

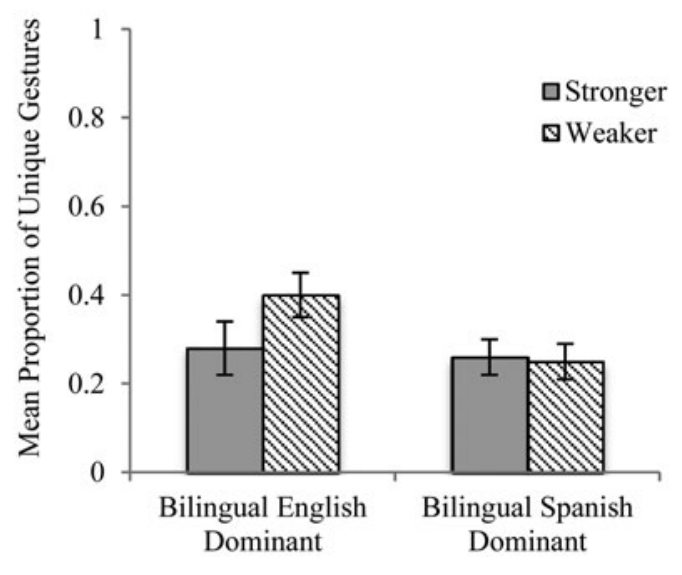

(b) PARENTAL TRANSLATION
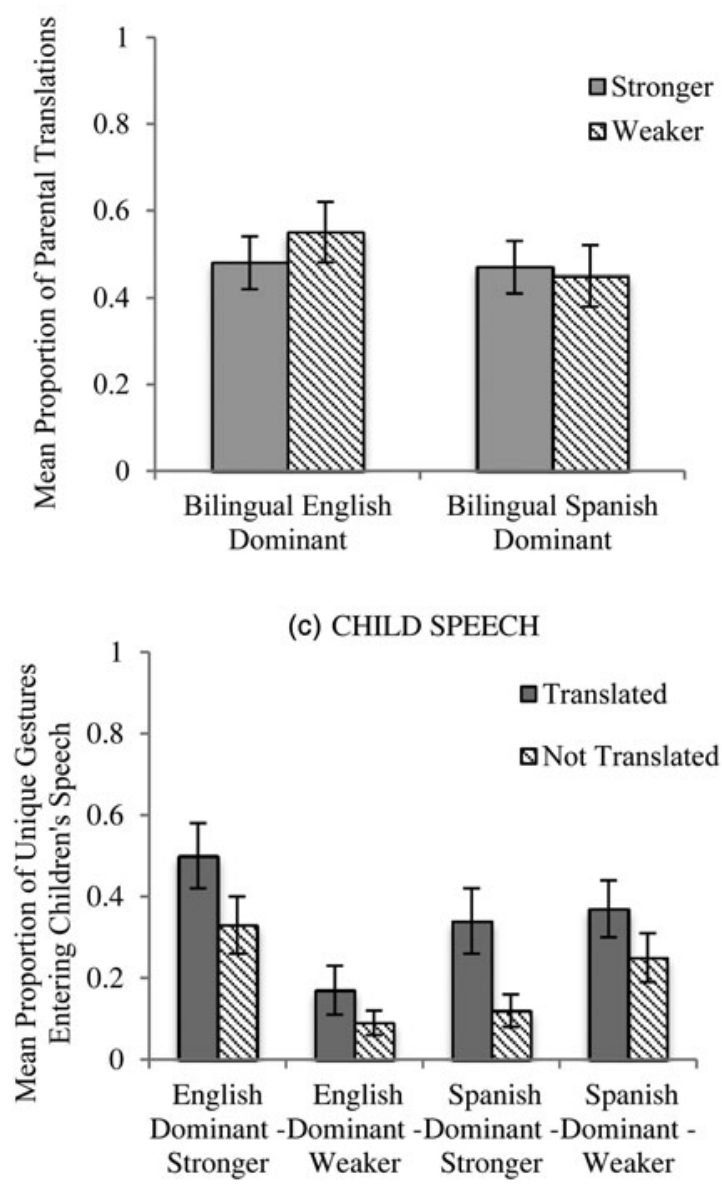

Figure 2. Mean proportion of referents bilingual children identified uniquely in gesture at 2;6 (panel A), mean proportion of unique child gestures parents of bilinguals translated into words at 2;6 (panel B), and mean proportion of unique gestures entering bilingual children's spoken vocabulary as words at ages 3;0-3;6 (panel C) among English-dominant (left) and Spanish-dominant (right) children; error bars represent standard error. 
$\left(F(1,32)=10.97, p<.01, \eta_{\mathrm{p}}^{2}=.25\right)$. A significantly greater proportion of unique gestures entered the spoken vocabularies in the stronger language than in the weaker language, but only for the English-dominant children (Bonferroni, $p<.01$ ), and not for their Spanish-dominant peers (Bonferroni, $p=.26$ ). There was no two-way interaction between translation and language group $(F(1,32)=0.30, p=.59)$ or translation and dominance $(F(1,32)=0.72, p=.4)$, and no three-way interaction between translation, dominance, and language group $(F(1,32)=0.09, p=.77)$.

A few of the bilingual children (4 Spanish dominant, 2 English dominant) showed less dominance in one language -2 with $58 \%, 1$ with $56 \%, 1$ with $54 \%$, and two with $51 \%$ of their vocabularies coming from their dominant language, which might have affected the patterns we observed. Therefore, we next asked whether the effect of dominance remained the same if we excluded the 6 bilingual children who showed less pronounced differences in their dominance, and found the same pattern of results. Our results based on the reduced sample of 28 bilingual children showed no effect of dominance $(F(1,26)=0.80, p=.38)$, language group $(F(1,26)=0.87$, $p=.36)$, or dominance $\times$ language group interaction $(F(1,26)=1.04, p=.32)$ in the production of unique gestures. The pattern remained identical for parental translations - with no effect of dominance $(F(1,26)=1.03, p=.32)$, language group $(F(1,26)=0.02, p=.90)$, or dominance $\times$ language group interaction $(F(1,26)=0.02$, $p=.88)$. Last, examining the appearance of translated unique gesture referents in bilingual children's spoken repertoires as words, we also found the same pattern of results: no effect of dominance $(F(1,26)=2.774, p=.11)$ or language group $(F(1,26)$ $=0.37, p=.55)$, but a main effect of translation $(F(1,26)=5.16, p=.03)$ - with a greater proportion of referents translated entering children's vocabularies as words than the ones that were not translated. Similarly, the analysis showed a significant dominance $\times$ language group interaction $(F(1,26)=13.50, p=.001)$ : English-dominant bilinguals were more likely to acquire translated referents in English (Bonferroni $p s<$ .001), while Spanish-dominant bilinguals were equally likely to acquire words in their stronger and weaker languages (Bonferroni $p s=.18$ ) - thus replicating the results we have observed with the whole sample of bilingual children.

Overall, these results suggest that bilingual children were equally likely to indicate objects uniquely in gesture in their stronger and weaker languages. Furthermore, parents were just as likely to translate their children's unique gesture referents in bilingual children's stronger and weaker languages. Importantly, however, the effect of this translation varied by language group-with English-dominant, but NOT Spanish-dominant, bilinguals acquiring a greater proportion of unique gesture referents as words in their stronger language than in their weaker language.

\section{Discussion}

In this study, we investigated whether bilingual children would follow a pattern akin to monolingual children in their production of unique gestures that identify referents, and the effect parental verbal input to such gestures might have in bilingual children's acquisition of similar vocabulary items in speech. We found that bilingual children were as likely as monolingual children to indicate referents uniquely in gesture before they did so with words. We also found that parents of bilingual children were as attentive to their children's unique gestures as parents of monolingual children, providing spoken labels for many of the referents children initially conveyed in gesture. Even more important, we found that these gesture referents that were 
translated into words by the parents were more likely to appear in children's vocabularies as words in both their weaker and dominant language than the referents that were not translated, showing the important role parental verbal input plays in the vocabulary development of bilingual children in each of their two languages.

\section{Monolinguals vs. bilinguals}

The bilingual children in our study were just as likely as their monolingual peers to indicate or request items uniquely with DEICTIC (e.g., holding up a ball or pointing at a doll) and GIVE (e.g., extending an open palm to request a doll) gestures before they did so in speech with words, and their parents were equally likely to translate these gestures into words. What might underlie the close similarity between the two groups? One possible explanation could be that the bilingual and monolingual children in our study had comparable vocabularies at our initial observation - which was by design. Given that the bilingual children in our study knew as many words across their two languages as the monolingual children knew in one, they were as likely as their monolingual peers to gesture about objects for which they did not yet have spoken labels. The comparable proportion of unique gesture production in the two groups, in turn, provided a similar amount of opportunities for the parents to respond. Consequently, parents in the two groups did NOT differ in the rate with which they translated the referents that their children uniquely identified in gesture. This finding further supports earlier work that showed no differences in the overall amount of speech input parents provide to their monolingual and bilingual children (e.g., De Houwer, 2009), and extends it to the domain of targeted verbal input to children's unique gestures.

Compared to earlier work (Dimitrova et al., 2016; Goldin-Meadow et al., 2007; Özçalışkan, 2007), however, the children in our study produced proportionally fewer unique gestures. One reason for this difference could be the language level of our participants. We know from previous work that gesture provides a relatively easy to use tool to communicate about referents - a tool that does not have the added cognitive burden of remembering and producing conventionalized symbols, namely words - particularly at the early stages of language learning. For the children in our study, speech was already becoming the preferred modality to identify referents, with the majority of the referents uniquely identified in speech $(70 \%)$ rather than in gesture $(30 \%)$ for both monolinguals and bilinguals. Thus, in contrast to the earlier work that relied on children at the one-word stage (ages $1 ; 0-1 ; 6$ ), all of the children in our study were already producing word-word combinations, and thus had to rely on gesture less than younger children in identifying referents. Nonetheless, the children used gesture to indicate or request referents that they could not yet express in speech, suggesting that gesture continues to be part of the vocabulary development process even after the onset of first words and sentences. Also, compared to earlier work (Dimitrova et al., 2016; Goldin-Meadow et al., 2007), the parents in our study translated a smaller proportion of their children's unique gesture referents into words. This might be largely due to parents' fine-tuning to the changing communicative needs of their children. An earlier study (Bornstein, Tamis-LeMonda, Hahn, \& Haynes, 2008) that followed monolingual children from age $1 ; 0$ to $2 ; 0$ found that maternal responses involving descriptions (e.g., "that is a pretzel") showed a decline over time, while maternal responses that elicited input from children, such as prompts (e.g., "feed it") and questions (e.g., "what is it?") 
increased with child age. Parents of bilingual children in our study might be showing a similar developmental fine-tuning to their children in the kinds of verbal input that they provided. The children already knew the labels for a substantial number of the referents; as such, parents may have preferred using conversation-eliciting responses instead of labeling, to further scaffold the more complex communication skills of their children - a possible explanation that needs to be tested in future work.

Our findings also highlight the need for additional longitudinal studies that examine the interplay between child unique gesture and parental verbal input on the acquisition of new vocabulary items in younger bilingual children who are at the cusp of producing their first words. Future studies that examine the transitional period during which children initially rely on gesture to identify referents and then eventually use words to label the same referents will provide a more comprehensive view of the effect of targeted verbal input to child gesture on vocabulary development among bilingual children.

Our study also showed, for the first time, that parental translations of child gesture had positive effects on bilingual children's acquisition of new words, and at rates comparable to monolingual children, extending earlier findings with monolingual children at the one-word stage (Dimitrova et al., 2016; Goldin-Meadow et al., 2007) to monolingual and bilingual children at the two-word stage. Our findings thus reaffirm that the quality and quantity of parent speech plays an equally important role in bilingual and monolingual language acquisition (Hoff, 2006; Pearson, Fernandez, Lewedeg, \& Oller, 1997). In addition, our study points out new evidence that bilingual children - and specifically their gestures - elicit meaningful parent speech, thus playing an important role in their lexical development. The parental translations children elicit with their unique gestures might be providing the critical instruction they need to acquire words they cannot yet label in speech.

Our study also further supported earlier work (Pearson et al., 1993) showing that bilingual children know as many words across both languages as monolingual children know in one. In showing that bilingual and monolingual children acquired translated gesture referents at similar rates, our findings also unveiled a crucial mechanism through which bilingual children and monolingual children might attain comparable vocabulary sizes in their languages.

Interestingly, though non-significant, the proportion of acquired words was slightly lower for bilingual children, compared to their monolingual peers. One possible reason for this could be bilingual children's propensity to NOT produce two labels (one per language) for a single referent, such as labeling a cat as both gato and cat. There is evidence that suggests that bilingual children's expressive vocabularies overlap relatively little across their two languages (21-30\%; Mancilla-Martinez, Pan, \& Vagh, 2011; Pearson et al., 1993). It is thus possible that, even if the bilingual children in our study identified the same referent in gesture during both the Spanish and the English interaction, they might have opted to produce the word only in one language (Spanish or English) in subsequent observations, resulting in fewer unique gesture referents entering their vocabularies as words.

\section{Stronger vs. weaker language}

The bilingual children in our study were stronger in one of their languages, which was part of our design for the study. However, they showed no effect of dominance (or language group) in their production of gestures identifying referents, contrary to our 
predictions, and contrary to the fact that they had significantly different vocabulary sizes in their weaker vs. stronger languages at the initial observation (EOWPVT; $\mathrm{M}_{\text {STRONGER }}=12.64$ vs. $\left.M_{\text {WEAKER }}=3.15, t(33)=4.99, p<.01\right)$.

One reason why the bilingual children did not use more unique gestures in their weaker language could be because they mixed the two languages. There is considerable evidence that suggests that young bilingual children frequently borrow words from their other language, if they do not know the word in the language they are speaking (Field, 2011; Paradis, Nicoladis, \& Genesee, 2000), and the bilingual children in our study were no exception. While their parents complied with our explicit instruction not to mix their two languages during the parent-child interaction by mixing on less than $2 \%$ of their utterances, all 34 of the bilingual children in our study mixed English and Spanish during their interactions with their parents, rather than speaking one language per interaction as instructed (i.e., English only vs. Spanish only). On average, the bilingual children rarely mixed languages (2\%) within their utterances (i.e., using English and Spanish within a sentence). However, they produced $15 \%$ of their utterances in Spanish during the English interaction and $20 \%$ of their utterances in English during the Spanish interaction. Furthermore, they named a majority of the referents in their stronger language (65\%) and a smaller percentage of them in their weaker language (35\%) in their interactions across the two languages. That is, when the children did not have the label for a referent in their weaker language, they would borrow the word from their stronger language, instead of using gesture to identify the referent.

Another reason why bilingual children did not use more unique gestures in their weaker language might be the relative complexity of the communicative context in which these gestures were elicited. Nicoladis (2007) found that the gap in the number of gestures bilinguals used in their weaker and stronger language widened as the task became more complex. The bilingual children in our study engaged in a relatively easy task of one-on-one interactions with their parents. It remains a possibility that the children in our study would have shown more pronounced differences in their production of unique gestures in their two languages if the demands of the task were more challenging - a possibility that can be addressed in future work.

Our results also showed that parents provided similar levels of verbal input (i.e., translations) in both languages when responding to their children's unique gestures in English and Spanish. This goes against earlier work that suggests that parents of bilingual children proportionally spend less time speaking in the child's weaker language (De Houwer, 2007). A likely explanation for the difference in findings could be that the bilingual children in our study provided their parents with equal opportunities to respond by producing similar proportions of unique gestures in their stronger and weaker languages. An alternative, yet likely, possibility could be the design of our experiment, which imposed a more controlled use of the two languages. Bilingual children and their parents were explicitly asked to use only one of their two languages in each of the two interactions - a request that was followed strongly by the parents, but not by the children. Previous work largely relied on more naturalistic environments, in which children and parents could opt to use one language or the other at their own will (De Houwer, 2007; Place \& Hoff, 2016). In such a situation, bilingual children get greater exposure to their dominant language at home, and also spend more time speaking their dominant language with their parents (Hoff et al., 2012). This, in turn, might give parents greater opportunities to label the referents in the child's dominant language than in their weaker language. 
Future studies that examine children's unique gesture production and parental verbal response to such gestures in more naturalistic environments can shed further light on the role dominance could play in this process.

Given the age range of our participants, many (35-41\%) were attending preschools both within the monolingual (14/34) and the bilingual (12/34) group. The primary medium of instruction in these preschools was English, which might have had an effect on bilingual children's emerging vocabularies in their two languages. However, recent work (Hoff, Giguere, Quinn, \& Lauro, unpublished observations) examining such effects in a larger sample of bilingual children which included the ones in our study, showed no effect of preschool attendance on bilingual children's language abilities.

The bilingual children in our study also acquired a greater proportion of their unique gestures as words in subsequent months in their stronger language as opposed to their weaker language, but only if the stronger language was English. That is, English-dominant bilingual children in our study made the most gains in their stronger language; in contrast, Spanish-dominant bilingual children made similar gains in their stronger and weaker languages. This difference could be explained by changes in language proficiency over the course of our observations. At our final observation at child age 3;6, the bilingual English-dominant children remained English dominant $\left(\right.$ EOWPVT; $M_{\text {ENGLISH }}=37.07$ vs. $\left.M_{\text {SPANISH }}=5.30 ; t(13) 7.75, p<.01\right)$. In contrast, the bilingual Spanish-dominant children lost their dominance in Spanish and became comparable in their vocabulary size in their two languages (EOWPVT; $M_{\mathrm{ENGLISH}}=$ 23.0 vs. $\left.M_{\text {SPANISH }}=23.0, t(9)=0.11, p=.90\right)$. This is consistent with previous findings showing that bilingual children's vocabulary shows more steady gains over time in English than in Spanish for both English-dominant and Spanish-dominant bilinguals (Hoff et al., 2012). The observed shift in proficiency is possibly due to a change in parent input at home. For example, Prevoo, Mesman, Van Ijzendoorn, and Piper (2011) showed that Turkish-Dutch bilingual mothers increased their use of Dutch at home in response to their two-year-old children's increasing usage of Dutch. Similarly, Goodz (1989) showed that when French-English bilingual children mix their second and first languages in speech, their mothers increase their use of the second language. For instance, when a child would address them with a mixed utterance, their mothers would often respond by continuing the conversation using mixed utterances instead of strictly adhering to the first language. It is likely that, as the bilingual children in our study approached school age, their caregivers increased their use of English in the home, thus contributing to a dominance change for the bilingual Spanish-dominant children. Consequently, the bilingual children's propensity to produce words for translated gestured items depended on their concurrent language dominance, with more spoken vocabulary items appearing in English.

Our study controlled for a variety of factors that are known to influence bilingual vocabulary development, such as family SES and time of exposure the child had to each language. At the same time, our study did not account for the influence of the majority language in the community outside the home. Future research that examines children's gesture, and the verbal responses they receive to such gestures outside the home, can shed further light on the role other interlocutors (peers, teachers) might play in providing a helping hand to the vocabulary development in bilingual children across different language contexts.

In conclusion, our study shows that gesture plays an important role in bilingual children's vocabulary development - as it does for monolingual children. Bilingual 
children continue to indicate a substantial number of referents uniquely in gesture even after they begin to produce word-word combinations, and parents respond to these gestures, translating them into words - a pattern that remains robust in children's stronger and weaker languages. The unique gestures, when translated by the parents, are more likely to enter the vocabularies of bilingual children as words - a pattern that becomes particularly pronounced for the stronger language but only if it is the majority language of the larger community.

Acknowledgement. Funding from NIH HD068421, Georgia State University Language and Literacy Initiative.

\section{References}

Acredolo, L. P., Goodwyn, S. W. (1985). Symbolic gesturing in language development. Human Development, 28(1), 40-9.

Bates, E. (1976). Language and context: the acquisition of pragmatics. New York: Academic Press.

Bates, E., Benigni, L., Bretherton, I., Camaioni, L., \& Volterra, V. (1979). The emergence of symbols: communication and cognition in infancy. New York: Academic Press.

Bornstein, M. H., Tamis-LeMonda, C. S., Hahn, C.-S., \& Haynes, O. M. (2008). Maternal responsiveness to young children at three ages: longitudinal analysis of a multidimensional, modular, and specific parenting construct. Developmental Psychology, 44(3), 867-74.

Brownell, R. (Ed.). (2000). Expressive One-Word Picture Vocabulary Test. Novato, CA: Academic Therapy Publications.

Brownell, R. (Ed.). (2001). Expressive One-Word Picture Vocabulary Test manual: Spanish-English bilingual edition. Novato, CA: Academic Therapy Publications.

Core, C., Hoff, E., Rumiche, R., \& Señor, M. (2013). Total and conceptual vocabulary in Spanish-English bilinguals from 22 to 30 months: implications for assessment. Journal of Speech, Language, and Hearing Research, 56(5), 1637-49.

De Houwer, A. (2007). Parental language input patterns and children's bilingual use. Applied Psycholinguistics, 28(3), 411-24.

De Houwer, A. (2009). Bilingual first language acquisition. Bristol: Multilingual Matters.

Dimitrova, N., Özçalışkan, Ş., \& Adamson, L. B. (2016). Parents' translations of child gesture facilitate word learning in children with autism, Down syndrome and typical development. Journal of Autism and Developmental Disorders, 46(1), 221-31.

Fenson, L., Marchman, V. A., Thal, D. J., Dale, P. S., Reznick, J. S., \& Bates, E. (2007). MacArthur-Bates Communicative Development Inventories: user's guide and technical manual. Baltimore, MD: Brookes.

Field, F. W. (2011). Key concepts in bilingualism. Basingstoke: Palgrave Macmillan.

Goldin-Meadow, S., Goodrich, W., Sauer, E., \& Iverson, J. (2007). Young children use their hands to tell their mothers what to say. Developmental Science, 10(6), 778-85.

Goodz, N. S. (1989). Parental language mixing in bilingual families. Infant Mental Health Journal, 10(1), $25-44$.

Hammer, C. S., Davison, M. D., Lawrence, F. R., \& Miccio, A. W. (2009). The effect of maternal language on bilingual children's vocabulary and emergent literacy development during Head Start and kindergarten. Scientific Studies of Reading, 13(2), 99-121.

Hoff, E. (2006). How social contexts support and shape language development. Developmental Review, 26(1), 55-88.

Hoff, E. (2017). Language development in Spanish-English dual language learners. Unpublished manuscript.

Hoff, E., Core, C., Place, S., Rumiche, R., Señor, M., \& Parra, M. (2012). Dual language exposure and early bilingual development. Journal of Child Language, 39(1), 1-27.

Iverson, J. M., Capirci, O., \& Caselli, M. C. (1994). From communication to language in two modalities. Cognitive Development, 9(1), 23-43.

Iverson, J. M., \& Goldin-Meadow, S. (2005). Gesture paves the way for language development. Psychological Science, 16(5), 367-71. 
Jackson-Maldonado, D., Thal, D., Marchman, V., Newton, T., Fenson, L., \& Conboy, B. (2005). Inventarios MacArthur-Bates del Desarrollo de Habilidades Comunicativas. User's guide and technical manual (2003). Baltimore, MD: Paul H. Brookes.

MacWhinney, B. (2000). The CHILDES Project: tools for Analyzing Talk (3rd ed.). Mahwah, NJ: Lawrence Erlbaum Associates.

Mancilla-Martinez, J., Pan, B. A., \& Vagh, S. B. (2011). Assessing the productive vocabulary of SpanishEnglish bilingual toddlers from low-income families. Applied Psycholinguistics, 32(2), 333-57.

Masur, E. F. (1982). Mothers' responses to infants' object-related gestures: influences on lexical development. Journal of Child Language, 9(1), 23-30.

Mayberry, R. I., \& Nicoladis, E. (2000). Gesture reflects language development: evidence from bilingual children. Current Directions in Psychological Science, 9(6), 192-6.

Nicoladis, E. (2002). Some gestures develop in conjunction with spoken language development and others don't: evidence from bilingual preschoolers. Journal of Nonverbal Behavior, 26(4), 241-66.

Nicoladis, E. (2007). The effect of bilingualism on the use of manual gestures. Applied Psycholinguistics, 28(3), 441-54.

Nicoladis, E., Mayberry, R. I., \& Genesee, F. (1999). Gesture and early bilingual development. Developmental Psychology, 35(2), 514-26.

Oller, D. K., \& Eilers, R. E. (2002). Language and literacy in bilingual children (vol. 2). Clevedon: Multilingual Matters.

Özçalışkan, Ş. (2007). Metaphors we move by: children's developing understanding of metaphorical motion in typologically distinct languages. Metaphor and Symbol, 22(2), 147-68.

Özçalışkan, Ş., Adamson, L. B., \& Dimitrova, N. (2016). Early deictic but not other gestures predict later vocabulary in both typical development and autism. Autism, 20(6), 754-63.

Özçalışkan, Ş., Adamson, L. B., Dimitrova, N., \& Baumann, S. (2017). Early gesture provides a helping hand to spoken vocabulary development for children with autism, Down syndrome and typical development. Journal of Cognition and Development, 18(3), 325-37.

Özçalışkan, Ş., Adamson, L. B., Dimitrova, N., \& Baumann, S. (2018). Do parents model gestures differently when children's gestures differ? Journal of Autism and Developmental Disorders, 48(5), 1492-507.

Özçalışkan, Ş., Gentner, D., \& Goldin-Meadow, S. (2014). Do iconic gestures pave the way for children's early verbs? Applied Psycholinguistics, 35(6), 1143-62.

Özçalışkan, Ş., \& Goldin-Meadow, S. (2005a). Gesture is at the cutting edge of early language development. Cognition, 96(3), B101-B113.

Özçalişkan, Ş., \& Goldin-Meadow, S. (2005b). Do parents lead their children by the hand? Journal of Child Language, 32(3), 481-505.

Özçalışkan, S., \& Goldin-Meadow, S. (2006). How gesture helps children construct language. In B. Kelly \& E. Clark (Eds.), Constructions in acquisition (pp. 31-58). Palo Alto, CA: CSLI Publications.

Özçalıșkan, Ş., \& Goldin-Meadow, S. (2011). Is there an iconic gesture spurt at 26 months? In G. Stam \& M. Ishino (Eds.), Integrating gestures: the interdisciplinary nature of gesture (pp. 163-74). Amsterdam: John Benjamins.

Paradis, J., Nicoladis, E., \& Genesee, F. (2000). Early emergence of structural constraints on code-mixing: evidence from French-English bilingual children. Bilingualism: Language and Cognition, 3(3), 245-61.

Pearson, B. Z., Fernandez, S. C., Lewedeg, V., \& Oller, D. K. (1997). The relation of input factors to lexical learning by bilingual infants. Applied Psycholinguistics, 18(1), 41-58.

Pearson, B. Z., Fernández, S. C., \& Oller, D. K. (1993). Lexical development in bilingual infants and toddlers: comparison to monolingual norms. Language Learning, 43(1), 93-120.

Petitto, L. A. (1992). Modularity and constraints in early lexical acquisition: evidence from children's early language and gesture. In M. R. Gunnar \& M. Maratsos (Eds.), The Minnesota symposia on child psychology, vol. 25: modularity and constraints in language and cognition (pp. 25-58). Hillsdale, NJ: Lawrence Erlbaum Associates.

Place, S., \& Hoff, E. (2016). Effects and noneffects of input in bilingual environments on dual language skills in 21/2-year-olds. Bilingualism: Language and Cognition, 19(5), 1023-41.

Prevoo, M. J., Mesman, J., Van Ijzendoorn, M. H., \& Pieper, S. (2011). Bilingual toddlers reap the language they sow: ethnic minority toddlers' childcare attendance increases maternal host language use. Journal of Multilingual and Multicultural Development, 32(6), 561-76. 
Rowe, M. L., Özçalışkan, Ş., \& Goldin-Meadow, S. (2008). Learning words by hand: gesture's role in predicting vocabulary development. First Language, 28(2), 182-99.

Tomasello, M., Carpenter, M., \& Liszkowski, U. (2007). A new look at infant pointing. Child Development, 78(3), 705-22.

Weiten, W. (2007). Psychology: themes and variations. Belmont, CA: Cengage Learning.

\section{Appendix}

Correlation between bilingual children's assessment scores and language use in English and Spanish at age $2 ; 6$

\begin{tabular}{lcccc}
\hline Measure & $\begin{array}{c}\text { English } \\
\text { word types }\end{array}$ & $\begin{array}{c}\text { Spanish } \\
\text { word types }\end{array}$ & $\begin{array}{c}\text { English } \\
\text { word tokens }\end{array}$ & $\begin{array}{c}\text { Spanish } \\
\text { word tokens }\end{array}$ \\
\hline MCDI $(n=29)$ & $0.77^{\star \star}$ & -0.29 & $0.81^{\star \star}$ & -2.7 \\
\hline IDHC $(n=31)$ & -0.32 & $0.88^{\star \star}$ & -0.35 & $0.77^{\star \star}$ \\
\hline EOWPVT English $(n=34)$ & $0.75^{\star \star}$ & $-0.46^{\star}$ & $0.74^{\star \star}$ & $-0.45^{\star}$ \\
\hline EOWPVT Spanish $(n=34)$ & $-0.46^{\star}$ & $0.62^{\star \star}$ & $-0.47^{\star}$ & $0.46^{\star \star}$ \\
\hline
\end{tabular}

Notes. ${ }^{*} p<.05,{ }^{\star *} p<.001$.

Cite this article: Limia V, Özçalişkan Ş, Hoff E (2019). Do parents provide a helping hand to vocabulary development in bilingual children? Journal of Child Language 46, 501-521. https://doi.org/10.1017/ S0305000918000594 